trabalho crítico

com os conceitos 


\title{
A criança e a escolha do sexo
}

\section{Maria Vitoria Fonseca Bittencourt}

\begin{abstract}
Resumo
O trabalho se propõe discutir a escolha do sexo na criança. Para desdobrar a questão da escolha do sexo na criança, uma expressão é indispensável: o gozo do corpo. A primeira manifestação de gozo é aquela em que a criança jubila diante de sua imagem no espelho. Mas, ao se fazer um corpo, advém a confrontação com a realidade sexual, que é o que há de mais hetero. O caso de Hans vem ilustrar esse gozo estrangeiro, fundamento de seu sintoma fóbico. Daí o tempo de sua "entrada no real" por meio de teorias sexuais infantis que vão produzir um saber, operando, assim, uma conjunção gozo e significante. Desse modo, escolher o sexo na busca da identidade se revela ilusório, pois não basta ter um corpo como garantia, entrando em jogo ter ou não ter o falo.
\end{abstract}

\section{Palavras-chave:}

Psicanálise; Criança; Sexualidade; Falo; Gozo; Escolha.

\section{The child and the choice of sex}

\begin{abstract}
The paper proposes to discuss the choice of sex in the child. To unfold the question of the choice of sex in the child, a term is indispensable: the jouissance of the body. The first manifestation of jouissance is the one in which the child jubilates before their image in the mirror. However, when making a body, comes the confrontation with the sexual reality, which is what is most hetero. The case of Hans illustrates this jouissance, the basis of his phobic symptom. Hence the time of his "entrance into the real" through infantile sexual theories that will produce knowledge, thus operating a conjunction of jouissance and signifier. So, choosing the sex in the search for identity proves to be illusory because it is not enough to have a body as a guarantee, and it is at stake whether or not to have the phallus.
\end{abstract}

\section{Keywords:}

Psychoanalysis; Child; Sexuality; Phallus; Jouissance; choice. 


\section{El niño y la elección del sexo}

\section{Resumen}

El trabajo se propone a discutir la elección del sexo en el niño. Para desdoblar la cuestión de la elección del sexo en el niño, un término es indispensable: el goce del cuerpo. La primera manifestación de goce es aquella en que el niño jubila delante de su imagen en el espejo. Pero, al hacerse un cuerpo, viene la confrontación con la realidad sexual, que es lo que hay de más hétero. El caso de Hans viene a ilustrar ese goce extranjero, fundamento de su síntoma fóbico. De ahí el tiempo de su "entrada en lo real" a través de teorías sexuales infantiles que van a producir un saber, operando así una conjunción goce y significante. Así, elegir el sexo en la búsqueda de la identidad se revela ilusorio, pues no basta tener un cuerpo como garantía, entrando en juego tener o no tener el falo.

\section{Palabras clave:}

Psicoanálisis; Infantil; Sexualidad; Falo; Goce; Elección.

\section{L'enfant et le choix du sexe}

\section{Résumé}

Cet article propose de discuter le choix du sexe chez l'enfant et, pour ce faire, une expression est indispensable : la jouissance du corps. La première manifestation de la jouissance est celle dans laquelle l'enfant se réjouit devant son image dans le miroir. Mais en se faisant un corps, la confrontation avec la réalité sexuelle, ce qu'il y a de plus hétéro apparaît. Le cas Hans vient illustrer cette jouissance étrangère, à la base de son symptôme phobique. D’où le temps de son « entrée dans le réel » via les théories sexuelles de l'enfant qui produisent un savoir, opérant ainsi une conjonction de jouissance et de signifiant. Choisir le sexe dans la recherche de l'identité alors s'avère illusoire, car il ne suffit pas d'avoir un corps comme garantie, et on voit entrer en jeu le fait d'avoir ou non le phallus.

\section{Mots-clés:}

Psychanalyse; Enfant; Sexualité; Phallus; Jouissance; Choix.

Esse tema me foi inspirado por algumas reportagens sobre crianças que escolhem o sexo oposto à sua anatomia em uma idade bastante precoce, apresentando uma "tendência de querer ser menina desde um ano de idade" (Kaz, 2017, p. 16). Nesses testemunhos, as crianças apresentam forte convicção de pertencer a um sexo que não é o sexo anatômico, manifestada muitas vezes como uma questão de vida ou morte. Essa demanda de mudança de sexo não se apresenta como uma escolha, mas como uma imposição; segundo o relato da mãe, "ele já quis cortar 
o pipi. Falou que quer morrer e voltar menina” (Kaz, 2017, p. 16). Poderíamos dizer que nesses casos se trata de uma oposição à verdade da anatomia como destino? Pois, em um primeiro momento, a anatomia é imposta ao sujeito, mas, depois, o discurso do Outro vem transmitir a interpretação de seu sexo. Ou seja, a anatomia faz parte do destino; contudo, segundo Freud, são suas consequências psíquicas que devem ser consideradas. Ao abordar o sexo pela via do gozo e da linguagem, Lacan indica a necessidade de subordinar o gozo, sobretudo do corpo, a um significante, bem longe da anatomia.

Essa escolha de mudança de sexo tem consequências orgânicas muito importantes, pois o pré-adolescente vai utilizar um bloqueador para retardar a puberdade, e aos 16 anos vai começar a tomar o hormônio do sexo oposto para ser operado aos 21 anos.

Essa certeza do sexo vem contrastar com o que Lacan chama de "opacidade sexual", que não permite "um conhecimento verdadeiro do sexual" (Lacan, 19751976/2005, p. 64). Esse conhecimento é, desde o início, “enganador”, pois não existe uma resposta instintual que oriente para a escolha do sexo e do parceiro, não existe saber que responde à questão do ser sexuado. O que está em jogo nessa escolha infantil? Como a psicanálise pode responder a essa questão de mudança de sexo na criança?

\section{Freud e Lacan}

Para Freud, a diferença sexual é um processo complexo, articulado com o desenvolvimento da pulsão sexual, pois os dois sexos são submetidos a uma única libido: fálica. A diferença se estabelece na articulação entre o complexo de Édipo e o complexo de castração. Para o menino, o complexo de Édipo é dissolvido pela ameaça da castração. Para a menina, ocorre o inverso; ela entra no Édipo pela castração, no qual permanecerá com sua reivindicação do penisneid e seu desejo de ter uma criança em compensação. Porém, é bom lembrar que, para Freud, o resultado nunca é puro, pois não se encontra pura masculinidade ou feminilidade no sentido psicológico, nem biológico. As pulsões não conhecem a diferença dos sexos, pois, para Freud, o sexual é a procura do prazer pela excitação das zonas erógenas.

Para Lacan, contudo, antes de ele introduzir o termo sexuação, propõe o termo “assunção" para apreender a implicação subjetiva do sexo para o sujeito. "Há no Édipo a assunção pelo sujeito de seu próprio sexo” (Lacan, 1957-1958/1998, p. 166), que remete à dimensão de escolha para além da biologia e do estado civil. Essa posição sexuada implica que o sujeito se inscreva sob o significante fálico, ou seja, o sujeito deve consentir ou não à inscrição da castração. Nessa primeira abordagem conceitual, a construção da identidade sexual passa pela via do Outro, pelo discurso do Outro. "Pelo Outro que a ordem e a norma devem se instaurar que dizem ao sujeito o que deve fazer como homem ou como mulher" (Lacan, 1964/1998, p. 849). Porém, se os significantes vêm do Outro, se o sujeito é deter- 
minado pelo significante, o que poderá exercer como escolha? Trata-se de uma resposta do simbólico que não é suficiente para a escolha do sexo. As personalidades as if, estudadas por Helene Deutsch, ilustram como o sujeito pode construir uma identidade sexual imaginária conformando-se à imagem de seu sexo, o que facilita o laço social e o laço com o parceiro, porém sua consistência é frágil, muitas vezes não bastando na hora da verdade do corpo a corpo sexuado. Na clínica, encontramos casos que testemunham uma solução que engaja o gozo ligado ao corpo e que não passa pelo significante.

Outra dimensão é exigida, pois se trata de corpo habitado de gozo. Lacan propõe o termo sexuação para dar conta daquilo que amarra a relação do sujeito ao gozo: a função fálica. Uma dimensão que não é redutível às oposições significantes, nem à lógica de atributos, mas exige uma construção singular do gozo e suas modalidades na relação com o outro sexo.

\section{Caso Hans}

O caso Hans pode ilustrar essas concepções da escolha na criança em suas duas vertentes: desejo e gozo. No início, Hans estava muito preocupado com essa parte de seu corpo - seu pênis. Ele começa uma espécie de inquérito sobre quem tem e quem não tem o pênis, e um jogo de exibicionismo se instala entre a criança e sua mãe. Hans está no lugar do objeto do desejo de sua mãe - o falo - em uma posição de preencher o que lhe falta. Ele passa seu tempo a exibir seu pênis e a olhar o corpo de sua mãe, em que a dimensão escópica é prevalente. Lacan evoca a felicidade de Hans nesse período, em que ele aprende a dar prazer à sua mãe ao lhe oferecer o falo em sua própria pessoa.

Esse paraíso chega ao fim com o nascimento da irmã e principalmente com a intrusão de um gozo masturbatório que se torna real, assim como o pênis. A criança se confronta com "a hiância que há entre satisfazer uma imagem e ter alguma coisa de real a apresentar” (Lacan, 1956-1957/1994, p. 226). Dessa irrupção de gozo surge a angústia, e a fobia se instala. Hans não quer mais sair por medo do cavalo que morde. Assim, a resposta ao apelo do pai para cortar a relação dual com a mãe se apresenta sob a forma do significante cavalo, que vem suprir a carência do pai. Assim, há a emergência de algo que vem perturbar a relação do ser falante com seu próprio corpo, o gozo. Para ordenar essa intrusão de gozo, ele apela ao significante cavalo, o que vem demonstrar que a linguagem funciona na origem em suplência do gozo sexual. Isso quer dizer que só se aborda o sexo pela linguagem.

Nesse exemplo, o sintoma vem como resposta do sujeito ao encontro com a realidade sexual, realidade especificada de que não há relação sexual, porque, nesse encontro, o sujeito só se confronta com o objeto de seu próprio gozo. Dizer que não há relação sexual é dizer que há a função fálica, como diz Lacan em 1972: “o gozo fálico é o obstáculo pelo qual o homem não consegue gozar do corpo da mulher, precisamente porque o de que ele goza é do gozo do órgão" (Lacan, 1972-1973/1982, p. 15). 
Lacan especifica que esse encontro não é autoerótico. É o que há de mais hetero. Ao usar o termo hetero, Lacan sublinha o que é de "estrangeiro", de Outro, no corpo do sujeito. Assim, "seu sintoma é a expressão, a significação dessa rejeição" (Lacan, 1975/1985, p. 13). Mas essa rejeição não se transforma em mudança de sexo, pois Hans não rejeita o significante falo, que vai surgir em suas construções imaginárias em torno do cavalo que morde. Hans comete o "erro comum": inscreveu na função fálica o gozo que experimentou.

Assim, a posição sexuada do sujeito se decide, pois Hans vai eleger o ideal materno, permanecendo identificado com o falo, em um estilo de um heterossexual passivo. Para Lacan, o que se passa não interessa a seu sexo, mas à sua relação com a mãe. Identificando-se com seu desejo, ele vai proceder por outra via que a da castração - a sublimação. Vai haver crianças imaginárias, crianças de seu espírito, como diretor de ópera, marcando, assim, seu destino singular.

\section{Criança versus adulto}

Se podemos deduzir que a orientação sexual e a escolha de objeto são estabelecidas na infância, qual seria a distinção entre a sexualidade adulta e a infantil? Ou seja, se há uma diferença, não se refere ao estatuto do gozo, nem ao do objeto. Tudo se resume ao fato de que a infância é o tempo da primeira vez de todas as experiências essenciais: encontro com o discurso do Outro e encontro com a experiências de gozo, noção que se designa como trauma original. Tempo das primeiras experiências da realidade sexual, como vimos em Hans. Pois o que está em jogo não concerne à realidade anatômica, nem tão pouco à orgânica. A primeira experiência de gozo pode ter como efeito a perplexidade do sujeito quando a operação do recalque não opera. A sexualidade do adulto se realiza com um parceiro real, na hora da verdade do corpo a corpo. Isso tem como consequências no nível da fantasia, na medida em que basta ao sujeito neurótico infantil a construção de uma fantasia que sustente o desejo, dando uma fórmula, o desejo do Outro, o que testemunha uma subjetivação da castração. Para o adulto, isso não é suficiente, pois terá de operar com a fantasia na hora do ato sexual, o que implica objetivar a castração. $\mathrm{O}$ encontro com a castração, objetivada no ato sexual e no gozo, pode relançar novamente a angústia e a formação de um sintoma.

\section{Destino e sexualidade}

A questão da mudança de sexo na criança é muito complexa e levanta questões para a psicanálise com crianças. Não temos ainda estudos referentes às consequências dessa escolha no caso de cirurgia. A literatura é vasta em autobiografias, a televisão nos mostra vários depoimentos, mas estudos clínicos são raros. Robert Stoller foi o primeiro a apresentar vários casos clínicos de adultos e talvez tenha favorecido, com sua teoria do gênero, os movimentos de reivindicação identitária. 
Além disso, existe uma especificidade quando se trata de crianças de 2 a 3 anos de idade, crianças que começam a falar, ainda tomadas pela coisa dos pais - a lalíngua que escuta - e que não fizeram ainda sua "entrada no real", ou seja, ainda estão no lugar de objeto real da fantasia da mãe. É preciso um longo caminho para se extrair desse lugar e entrar na dialética da identificação com o falo (no caso de neurose). Muitas vezes, essas crianças estão no tempo da construção de um sintoma, como vimos no caso de Hans, tempo das teorias sexuais infantis, fundamento de uma invenção de saber que leva a uma invenção do sintoma. Talvez por essa razão, os casos em que essa demanda se dirige ao analista são raros, pois não se trata de um sintoma que faz questão, mas de uma exigência que se impõe. Por isso, podemos compreender a resposta de Lacan na apresentação de um paciente transexual em Saint-Anne, em 1976: não acredita nas chances de "operação analítica" diante da certeza do sujeito quanto à operação cirúrgica.

Em seu artigo "Não há transexual fora do discurso da ciência", Vera Pollo afirma que se trata de um sintoma da contemporaneidade, resultante da afinidade do discurso da ciência com o discurso capitalista (Pollo, 2012, p. 129). O resultado se verifica na transformação do corpo em objeto de um gozo muito específico: o gozo do consumo, um gadget a ser consumido. O consumo visa a reduzir a falta pelo objeto que a preenche, cujo efeito esmaga o desejo do sujeito.

Para concluir, o que importa é interrogar aquilo que da infância determina não somente a sexualidade, mas o destino do sujeito. Em seu texto Felicidade e sintoma, Demoulin retoma uma frase de Lacan: "só há o falo para ser feliz, não seu portador" (Lacan, 1969-1970/1991, p. 84), e afirma: "só há o sintoma para ser feliz" (Demoulin, 2009, p. 170). Demoulin se apoia sobre o sintoma considerado como a maneira pela qual cada um goza de seu inconsciente: cada um com seu sintoma, que o sustenta na existência, que faz seu modo de gozo e sua identidade na separação com o Outro primordial. Sintoma que fixa seu desejo e pode fazer um destino singular. Nisso, a psicanálise pode operar.

\section{Referências bibliográficas}

Demoulin, C. (2009). Bonheur et symptôme. In L'en-je lacanien (N. 11, pp. 159172). Paris: Erès.

Kaz, R. (2017, maio). Retrato de uma menina. Revista Piauí, 128.

Lacan, J. (1956-1957/1994). Le séminaire livre IV: la relation d'objet. Paris: Seuil.

Lacan, J. (1957-1958/1998). Le séminaire livre V: les formations de l'inconscient. Paris: Seuil.

Lacan, J. (1964/1998). Position de l'inconscient (pp. 829-850). In J. Lacan. Écrits. Paris: Seuil.

Lacan, J. (1969-1970/1991). Le séminaire livre XVII: l'envers de la psychanalyse. Paris: Seuil. 
Lacan, J. (1972-1973/1982). O seminário livro XX: mais ainda. Rio de Janeiro: Jorge Zahar.

Lacan, J. (1975/1985). Conférence à Genève sur le symptôme (N. 5, pp. 5-23). In Bloc notes de psychanalyse. Genebra.

Lacan, J. (1975-1976/2005). Le séminaire livre XXIII: Le symptôme. Paris: Seuil.

Pollo, V. (2012). O medo que temos do corpo. Rio de Janeiro: Sete Letras.

Recebido: 06/10/2017

Aprovado: 24/01/2018 
